\title{
Sarcoma de Kaposi gástrico y Mycobacterium genavense
}

\author{
A. Benítez Roldán, C. González López, M. Díaz Delgado , A. Caunedo Álvarez, A. Domínguez \\ Castellanos ${ }^{2}$, F. Pellicer Bautista y J. M. Herrerías Gutiérrez
}

Servicios de Aparato Digestivo, ${ }^{1}$ Anatomía Patológica y ${ }^{2}$ Enfermedades Infecciosas. Hospital Universitario Virgen Macarena. Sevilla

Varón de 29 años, VIH positivo categoría C3, VHB crónica y diagnosticado de sarcoma de Kaposi cutáneo-mucoso tratado con adriamicina liposomal a dosis de $50 \mathrm{mg} / \mathrm{m}^{2}$ e infección crónica diseminada por Mycobacterium genavense. Presentó un deterioro progresivo de su estado general de 20 días de evolución, junto con fiebre, dolor abdominal, náuseas y vómitos, deposiciones diarreicas sin productos patológicos y dolor en costado derecho.

Se objetiva una anemia microcítica hipocrómica, unas proteínas totales $3,9 \mathrm{~g} / \mathrm{dl}$, albúmina $2,1 \mathrm{mg} / \mathrm{dl}$ y fosfatasa alcalina 238. En la tinción de Ziehl de las heces se observan abundantes BAAR y una situación de inmunosupresión severa CD4 + 24 .

Se realiza una ecografía abdominal que mostró una hepatomegalia con signos de hepatopatía difusa sin evidencia de hipertensión portal; ecografía doppler de miembro superior izquierdo y troncos supraaórticos donde se observan numerosas imágenes nodulares hipoecogénicas de 2 y $5 \mathrm{~cm}$ compatibles con adenopatías laterocervicales izquierdas.

En la fibrogastroenteroscopia se aprecian lesiones congestivas con mucosa faríngea compatible con sarcoma de Kaposi de mucosa oral. Lesión polipoidea de aspecto congestivo y vascular en curvatura mayor de estómago, no ulcerativa (Fig. 1).

El examen histológico de la muestra gástrica reveló una proliferación de células fusiformes con tendencia a la formación de canales vasculares disecando entre foveolas gástricas. Existía frecuente extravasación eritrocitaria. Dichas células

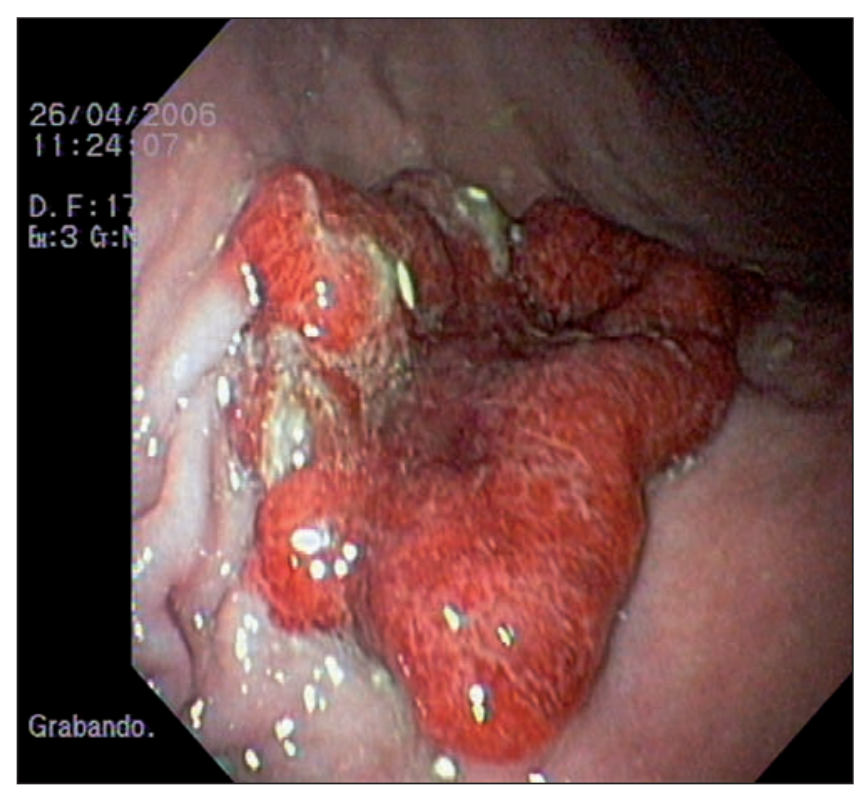

Fig. 1.

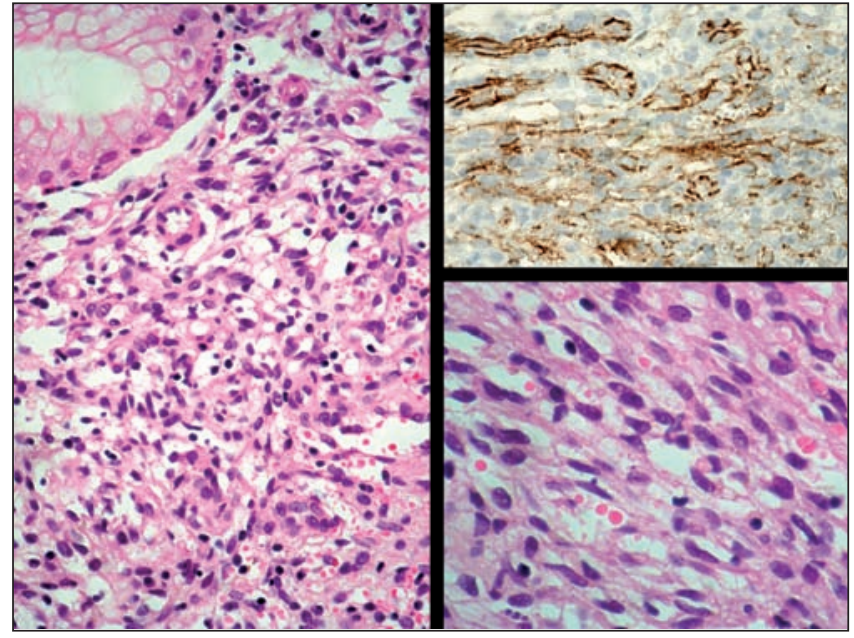

Fig. 2. 
fueron positivas para el marcador vascular CD31 (Fig. 2 derecha-arriba). No se observó un infiltrado linfoplasmocitario prominente existiendo ocasionales neutrófilos intraepiteliales (Fig. 2).

El paciente fue tratado con antirretrovirales tenofovir, emtricitabina, efavirez, tratamiento para la infección por Mycobacterium genavense, claritromicina $500 \mathrm{mg}$ cada 12 horas y rifambutina $300 \mathrm{mg}$ cada 24 horas para el sarcoma de Kaposi y seguimiento posteriormente por el servicio de oncología.

\section{COMENTARIOS}

El sarcoma de Kaposi es una neoplasia poco común que ocasionalmente se desarrolla en el tracto gastrointestinal en individuos inmunodeprimidos. Estar infectados por HHV8 es necesario para el desarrollo de todas las formas de presentación del sarcoma de Kaposi (1). Es una enfermedad que afecta fundamentalmente a varones. Tanto la forma clásica como las formas relacionadas con enfermos VIH se dan hasta quince veces más en hombres que en mujeres.

El tracto gastrointestinal está afectado hasta en un $40 \%$ de pacientes con sarcoma de Kaposi al inicio del diagnóstico y hasta un $80 \%$ cuando se hace autopsia.

Las lesiones gastrointestinales pueden ser asintomáticas o causar algún síntoma como pérdida de peso, dolor abdominal, náuseas y vómitos, síndrome de malabsorción, etc. (2,3).

Son importantes para el estadiaje del tumor y decidir el tratamiento la cantidad de CD4 y la carga viral.

La infección por Mycobacterium genavense se presenta casi exclusivamente en pacientes VIH con un recuento de CD4 $<100$ células $/ \mathrm{mm}^{3}$. La presentación clínica es similar a la de Mycobacterium Avium complex, se asocia a adenopatías masivas y organomegalias, especialmente esplenomegalia (4).

El paciente lleva un año de tratamiento con mejoría clínica pero sin eliminar completamente la micobacteria, siguen apareciendo BAAR en las heces, posiblemente porque continúa con menos de 100 CD4.

\section{BIBLIOGRAFÍA}

1. Sakagami J, Sogame Y, Kataoka K, et al. Endoscopic resection for the diagnosis of visceral Kaposi sarcoma. J Gastroenterol 2005; 40: 98-103.

2. Danzig JB, Brandt LJ, Reinus JF, et al. Gastrointestinal malignancy in patients with AIDS. Am J Gastroenterol 1991; 86: 175.

3. Laine L, Amerian J, Rarick M, et al. The response of symptomactic gastrointestinal Kaposi sarcoma to chemotherapy; A prospective evaluation using an endoscopic method of disease quantificacion. Am J Gastroenterol 1990; 85: 959.

4. Thomsen V, Dragsted UB, Bauer J, et al. Disseminated infection with Mycobacterium genavense: A challenge to physicans and mycobacteriologists. J Clin Microbiol 1999; 37: 3901. 